\title{
Severe Oropharyngeal Angioedema Caused by Propofol - A case report -
}

\author{
Departments of Anesthesiology and Pain Medicine, *Oral \& Maxillofacial Surgery and \\ ${ }^{\dagger}$ Internal Medicine, Ulsan University School of Medicine, Ulsan, Korea
}

Chul Ho Shin, M.D., Young Hee Lee, M.D., Young Min Kim, M.D., Se Hun Park, M.D., Iel Yong Sung, M.D.*, Seong Won Choi, M.D. ${ }^{\dagger}$, and Soon Eun Park, M.D.

Although propofol is thought to be a relatively safe intravenous anesthetic with regard to histamine release reactions, anaphylactoid reactions to propofol may sometimes occur, especially in patients with a history of allergy, atopy, or asthma. Here we report a patient with allergies to sesame leaves and cold medications who experienced an anaphylactic reaction with severe oropharyngeal edema a few minutes after receiving propofol $\left(\right.$ Anepol $^{\circledR}$ ). This finding suggests that propofol should be used with caution in patients with a history of allergy. Because profound airway edema can occur, the airway should be evaluated before extubation of the trachea. (Korean J Anesthesiol 2006; 50: S 68 70)

Key Words: airway, anaphylactic reaction, oropharyngeal edema, propofol.

As an anesthetic agent, propofol has several advantages compared with thiopental sodium, including smooth induction, rapid recovery, and low incidence of nausea, vomiting and allergic reactions. ${ }^{1,2)}$ Thus propofol is widely used not only for anesthesia but also for sedation during minor outpatient procedures and endoscopic examinations.

Several anaphylactoid reactions, however, have been reported with propofol such as the development of wheals on the skin and bronchospasm. ${ }^{3-5)}$

Here we report a case of anaphylactic reaction with life-threatening oropharyngeal edema, which occurred during propofol induction.

\section{CASE REPORT}

A previously healthy 18 -year-old male patient $(172 \mathrm{~cm}, 60 \mathrm{~kg}$, ASA class I) had general anesthesia for elective dental surgery. He had an allergy to sesame leaves and cold medications but no other remarkable medical history. Except for mildly increased WBC $(12,100 / \mathrm{UL})$ and polysegmented neutrophil $(79.8 \%)$ counts, other laboratory measurements were with normal ranges.

Received : April 6, 2006

Corresponding to : Soon Eun Park, Department of Anesthesiology and Pain Medicine, Ulsan University School of Medicine, 290-3 Jeonhadong, Dong-gu, Ulasn 682-060, Korea. Tel: 82-52-250-7244, Fax: 82-52-250-7249, E-mail: gamju@yahoo.co.kr
Following administration of $10 \mathrm{mg}$ of $1 \%$ lidocaine, anesthesia was induced with propofol $\left(\right.$ Anepol ${ }^{\circledR}$ ). After receiving $50 \mathrm{mg}$ propofol, the patient began coughing, and after injection of 120 $\mathrm{mg}$ propofol, his coughing worsened and reddish rashes began to erupt over his entire body. Immediately vecuronium bromide $8 \mathrm{mg}$ was administered intravenously.

The patient kept coughing and moving, which made mask ventilation difficult, therefore $100 \mathrm{mg}$ of thiopental sodium and 60 $\mathrm{mg}$ of lidocaine were administered. This improved the patient's ventilation, but the eruptions became worse with the face, trunk, and all extremities all being involved. In addition, eyelid edema also appeared. Oxygen saturation was well maintained above $98 \%$. His blood pressure fell to $72 / 30 \mathrm{mmHg}$ and his heart rate approached 125 beats/min. The patient was placed in the Trendelenburg position and given ephedrine $10 \mathrm{mg}$ intravenously, together with an increased infusion of intravenous fluids.

Following intravenous administration of piprinhydrinate (Plakon ${ }^{\mathbb{R}}$ ) $3 \mathrm{mg}$ and dexamethasone $5 \mathrm{mg}$, tracheal intubation (ETT size 7.0 RAE tube) was performed. Although edema was present in the oral cavity and epiglottis, intubation was performed without any difficulty. Oxygen saturation was never went below 98\%, and bronchospasm did not occur.

The patient's blood pressure was continuously monitored by radial artery cannulation. After a few minutes, his blood pressure increased to $110 / 42 \mathrm{mmHg}$ and his heart rate decreased to 91 
Chul Ho Shin, et al : Oropharyngeal Angioedema Caused by Propofol

beats/min. Results of arterial blood gas analysis showed $\mathrm{pH} 7.34$, $\mathrm{PaCO}_{2} 52 \mathrm{mmHg}, \mathrm{PaO}_{2} 406 \mathrm{mmHg}, \mathrm{Na}^{+} 138 \mathrm{mmol} / \mathrm{L}, \mathrm{K}^{+} 4.0$ $\mathrm{mmol} / \mathrm{L}$, and hematocrit $44 \%$.

The operation was done without any significant hemodynamic changes. The rashes disappeared, but the swelling of the eyelid and conjunctiva still remained. Airway evaluation was performed by bronchoscopy prior to extubation. Edema in the oral cavity was so severe that we could not check the upper airway. Therefore, the patient was transferred to the intensive care unit while intubated.

Although the oropharynx and hypopharynx remained edematous 4 hours later, as shown by bronchoscopy, it was enough to maintain airway patency. Therefore, the patient was extubated and moved to the general ward the next day without any problems.

Except for elevated WBC $(18,300 / \mathrm{UL})$ and polysegmented neutrophil $(87.2 \%)$ counts, no other laboratory abnormalities were found the following day. We found he had moderately elevated total IgE levels during food and respiratory tests, but his MAST allergy test response was negative for all other antigens.

We suspected propofol as the cause of the anaphylaxis. Both pin-prick and intradermal tests performed 3 months later against propofol, lidocaine, and vecuronium showed a positive response only to propofol.

\section{DISCUSSION}

Life-threatening oropharyngeal swelling without any severe circulatory collapse occurred during induction of propofol anesthesia in our patient, who had allergies to sesame leaves and cold medications. The propofol skin tests performed 3 months later were positive indicative of an allergic history, and he had an elevated total IgE level. These findings indicate that propofol was the cause of his anaphylactic reaction.

Propofol is an intravenous sedative-hypnotic anesthetic agent, similar in action to thiopental, which can be used to maintain anesthesia by constant infusion. However, propofol is more likely than other anesthetic drugs to cause an allergic reaction, with incidence of $2.0 \%$ of perioperative anaphylactic shock in France were attributed to propofol. ${ }^{6}$

Anaphylactic reactions during the induction of anesthesia can be caused by most anesthetic agents, including propofol, thiopental sodium, etomidate, and muscle relaxants, ${ }^{7-10)}$ with the latter being the causative agents in $60-80 \%$ of cases. Intraoperative allergic reactions occur once in every 5,000-25,000 inductions of anesthesia and have a $3.4 \%$ mortality rate. ${ }^{11)}$ More than $90 \%$ of the allergic reactions evoked by intravenous drugs occur within 5 minutes of administration.

Hypersensitivity reaction is the term used when the response of the immune system to a foreign antigen results in an adverse response in the host. These reactions can be divided into several types, by the effector molecules produced and activated during the process.

Type 1 hypersensitivity reaction (anaphylaxis) is in response to a specific allergen. When the specific allergen is introduced into the body, plasma cells release $\operatorname{IgE}$ antibodies during normal immune reactions, which bind strongly to Fc receptors located on the surface of mast cells or basophils. Cross-linking of these sensitized mast cells and basophils leads to their degranulation, and the mediators released, including histamine, induce various biophysiological reactions. ${ }^{12)}$

Anaphylaxis is caused not only by the effects of these compounds but by secondary reactions in other cells, including eosinophils, neutrophils, $\mathrm{T}$ lymphocytes, monocytes, and platelets. This leads to airway constriction, edema and erythema. Substances associated with anaphylaxis include histamine, protease, eosinophil chemotatic factor, neutrophil chemotactic factor, heparin, plateletactivating factor, leukotrienes, prostagladins, bradykinin and cytokines. ${ }^{13)}$

Upon release from mast cells, histamine combines with specific $\mathrm{H}_{1}, \mathrm{H}_{2}$ and $\mathrm{H}_{3}$ receptors on target cells. These histamine receptors have different distributions and effects. Most allergic reactions are mediated through binding to $\mathrm{H}_{1}$ receptor, resulting in visceral or bronchial smooth muscle constriction, increased vascular osmolality and mucus secretion by goblet cells, whereas histamine binding to $\mathrm{H}_{2}$ receptors can increase exocrine gland secretion. Leukotrienes and prostaglandins act more slowly than histamine because they are released during degranulation of the mast cells. Moreover, their actions are more potent and last longer than histamine. Leukotriene is a potent bronchoconstrictor, as well as increasing vessel permeability and mucus production. Prostaglandin $D_{2}$ is also a bronchoconstrictor. In addition, cytokines released by the mast cells are associated with type 1 hypersensitivity. ${ }^{14)}$

The initial formulation of propofol, cremophor EL, was found to be associated with high rates of complement mediated vascular spasms and anaphylactic reactions. ${ }^{3)}$ However, a new propofol formulation, using soybean oil, was found to cause clinically insignificant histamine release compared with other intravenous anesthetic agents. $^{15,16)}$

The use of a combination of $\mathrm{H}_{1}$ and $\mathrm{H}_{2}$ receptor antagonists has been found to have a good prophylactic effect on anaphylactic 
reactions in patients with a history of allergy and a high risk of histamine release during surgery. ${ }^{15)}$ However, propofol-induced anaphylactic reactions cannot be completely prevented. One study could not conclude that propofol can be safely used in patients with a history of allergy especially allergies to drugs or foods, or atopic dermatitis. ${ }^{8)}$ Most patients with anaphylactic reactions to propofol were those with asthma, drug allergies, and allergic rhinitis. ${ }^{7}$ Nevertheless, because the incidence is low, allergic history is not a reliable predictor for the occurrence of an allergic reaction to propofol and does not mandate that such patients should be investigated or pretreated, or that specific drugs be selected or avoided. $^{17)}$

In conclusion, careful investigation of a history of allergy may prevent propofol-induced anaphylaxis. In patients with a history of allergy, other intravenous anesthetic agents should be considered. When anaphylactic reactions to propofol occur, it is important to secure the airway and administer antihistamines and steroids. Even if hemodynamic changes are apparent or bronchial spasms occur it is important to administer epinephrine and aminophylline and rapid expansion of intravascular volume. Above all, these drugs must be readily available. Because profound oropharyngeal swelling can occur, as in this case, the airway must be evaluated before extubation of the trachea.

\section{REFERENCES}

1. Jung SS, Shin OY, Choi YK, Shin KI: Propofol and thiopentalenflurane: A comparison of anesthesia for laryngomicrosurgery. Kor J Anesthesiol 2000; 39: 314-9.

2. Stark RD, Binks SM, Dutka VN, O'Connor KM, Arnstein MJA, Glen JB: A review of the safety and tolerance of propofol (Diprivan). Postgrade Med 1985; 61(Suppl 3): 152-6.

3. Briggs LP, Clarke RSJ, Watkins J: An adverse reaction to the administration of disopropofol (Diprivan). Anaesthesia 1982; 32:
1099-101.

4. Leon-Casasola OA, Weiss A, Lema MJ: Anaphylaxis due to propofol. Anesthesiology 1992; 77: 384-6.

5. McHale S, Konieczko K: Anaphylactoid reaction to propofol. Anaesthesia 1993; 48: 446-7.

6. Mertes PM, Laxenaire MC, GERAP: Anaphylactic and anaphylactoid reactions occurring during anesthesia in France in 1999-2000. Anesthesiology 2003; 99: 536-45.

7. Laxenaire MC, Mata-Bermejo E, Moneret-Vautrin DA, Gueant JL: Life-threatening anaphylactoid reactions to propofol (Diprivan). Anesthesiology 1993; 78: 607-9.

8. Nishiyama T, Hanaoka K: Propofol-induced bronchoconstriction: two case report. Anesth Analg 2001; 93: 645-6.

9. Dolovich J, Evans S, Rosenbloom D, Goodacre R, Rafajac FO: Anaphylaxis due to thiopental sodium anesthesia. Can Med Assoc J 1980; 123: 292-4.

10. Fazackerley EJ, Martin AJ, Tolhurst-Cleaver CL, Watkins J: Anaphylactoid reaction following the use of etomidate. Anaesthesia 1988; 43: 953-4.

11. Weiss ME, Adkinson NF, Hirshman CA: Evaluation of allergic reactions in the perioperative period. Anesthesiology 1989; 71: 438-6.

12. Costa JJ, Weller PF, Galli SJ: The cells of the allergic response: Mast cells, basophils, and eosinophils. JAMA 1997; 278: 1815-22.

13. Wasserman SI: Mediators of immediate hypersensitivity. J Allergy Clin Immunol 1983; 72: 101-19.

14. Lazarus SC: Inflammation, inflammatory mediators, and mediator antagonists in asthma. J Clin Pharmacl 1998; 38: 577-82.

15. Kimura K, Adachi M, Kubo K: Histamine release during the induction of anesthesia with propofol in allergic patients: A comparison with the induction of anesthesia using midazolam-ketamine. Inflammation Research 1999; 48: 582-7.

16. Doenicke A, Lorenz W, Stanworth D, Duka T, Glen GB: Effects of propofol (Diprivan) on histamine release, immunoglobulin levels and activation of complement in healthy volunteers. Postgraduate Med J 1985; 61: 15-20.

17. Fisher MM, Outhred A, Bowey CJ: Can clinical anaphylaxis to anaesthetic drugs be predicted from allergic history? Br J Anaesth 1987; 59: 690-2. 